\title{
Differences in Incidence, Mortality and Survival of Breast Cancer by Regions and Countries in Asia and Contributing Factors
}

\author{
Yeonju Kim ${ }^{1 *}$, Keun-Young Yoo $^{2}$, Marc T Goodman ${ }^{3,4}$
}

\begin{abstract}
Although the incidence of breast cancer in Asia remains lower than in North America, Western Europe, and Oceania, rates have been increasing rapidly during the past few decades, and Asian countries now account for $40 \%$ of breast cancer cases diagnosed worldwide. Breast cancer mortality has also increased among Asian women, in contrast to decreased mortality in Northern America, Western Europe, and Oceania. These increased rates are associated with higher prevalence of breast cancer risk factors (e.g., reduced parity, delayed childbirth, increased obesity) that have accompanied economic development throughout the region. However, Asian regions (western, south-central, south-eastern, and eastern) and countries differ in the types and magnitude of changes in breast cancer risk factors, and cannot be viewed as a single homogeneous group. The objective of this paper was to contrast the heterogeneous epidemiology of breast cancer by Asian regions and countries, and to suggest potential avenues for future research.
\end{abstract}

Keywords: Breast cancer - incidence - mortality - survival - epidemiology - risk factor - Asia

Asian Pac J Cancer Prev, 16 (7), 2857-2870

\section{Introduction}

Breast cancer is the most common malignancy among women worldwide and in 140 of 184 countries, with an estimated 1.67 million estimated incident cases (Ferlay et al., 2013; Ferlay et al., 2015). The number of women with incident breast cancer in Asia was estimated at 651,000 in 2012, comprising $38.8 \%$ of all cases globally, followed by Europe (27.7\% of all cases) and North America (15.3\% of all cases). Of the 47 Asian countries discussed in this report, breast cancer is the leading malignancy among women in 39 of Asian countries, the second most common malignancy among women in 6 Asian countries, and the fifth most common malignancy in two countries, Mongolia and Bhutan (Ferlay et al., 2013).

Historically, breast cancer incidence has been highest in Northern America, Western and Northern Europe, and Australia/New Zealand, with rates ranging from 85.8 to 96.0 (Figure 1). [Note: All data in this report are expressed per 100,000 women, although only the rates are provided.] Breast cancer incidence rates in Asian countries are estimated at one-fourth to one-third of the rates in the traditionally high-risk countries, with an Asian average rate of 29.1 (Ferlay et al., 2013). However, in contrast to the overall stable rates in England (Westlake and Cooper, 2008), and in the United States (all ages, all race/ethnic groups combined) (DeSantis et al., 2014), breast cancer incidence has been increasing sharply in Asia (Shin et al., 2010b).

A large body of scientific literature supports the notion that the recent increase in breast cancer incidence among Asian women in Asia is attributable to economic development and adaptation of a more 'westernized' lifestyle, including delayed childbirth, reduced parity and breastfeeding, weight gain, and increased consumption of animal fat (Yoo et al., 2006; Long et al., 2010b; Moore et al., 2010a; Moore et al., 2010b; Moore et al., 2010c; Salim et al., 2010; Forouzanfar et al., 2011; Bhoo-Pathy et al., 2013). While these changes in risk-associated behaviors undoubtedly explain some of the recent elevations in breast cancer rates in Asia, the magnitude of the annual percent change in incidence is discrepant between countries. For example, the age standardized incidence rate (ASIR) for breast cancer among South Korean women increased by $44.9 \%$ between 1993 and 2002; whereas, breast cancer rates increased by $24.2 \%$ among Singaporean women and $5.2 \%$ among Filipinas during the same time period (Shin et al., 2010b). Clearly, Asian countries differ in the types and magnitude of changes in breast cancer risk factors and cannot be viewed as a homogeneous group. In this study, we aimed to examine the heterogeneous characteristics of breast cancer epidemiology by regions and countries in Asia and discuss of the contributing factors of the phenomena. 


\section{Materials and Methods}

Data sources for incidence, mortality, and survival

Data from the International Agency for Research on Cancer (IARC) were used primarily in the comparison of breast cancer incidence, mortality, and survival between Asian countries, including GLOBOCAN 2012, Cancer Incidence in Five Continents (CI5), the WHO Cancer Mortality database, and SurvCan (information all available at http://www-dep.iarc.fr/CancerMondial.htm). These data were supplemented, where necessary, by national publications and research papers.

\section{GLOBOCAN 2012}

GLOBOCAN is a comprehensive cancer registry database which provides contemporary estimates of cancer incidence, mortality and prevalence at the national level for 184 countries (Ferlay et al., 2010; Ferlay et al., 2013). The latest version, GLOBOCAN 2012, was made available for analysis in late 2014 (http://globocan.iarc. fr/Default.aspx) (Ferlay et al., 2015). We adapted the GLOBOCAN 2012 categorization scheme which grouped 47 Asian countries into four regions: eastern (5 countries), south-eastern (11 countries), south-central (14 countries), and western (17 countries) (Table 1). Country lists in GLOBOCAN are based on United Nations' criteria, so Taiwan was not included as a separate sovereign nation. We reviewed the breast cancer rates for Taiwan from other sources (Chiang et al., 2010; Shin et al., 2010b) and added Taiwan to the list of eastern Asian countries.

Because GLOBOCAN 2012 compiles and systematically analyzes data from many countries throughout the world, it is the most useful and reliable source for cross-sectional comparisons of cancer incidence and mortality between countries. However, several countries included in GLOBOCAN lack populationbased cancer registries and available population-specific information, so cancer rates for these countries were estimated by applying cancer rates and population profiles from neighboring countries (detailed information available at: http://globocan.iarc.fr/Pages/DataSource_ and_methods.aspx). We were cautious in interpreting these data.

The comparison of cancer estimates from different versions of GLOBOCAN is not recommended because sources of data have improved and methodology has changed. Thus, CI5 and the WHO cancer mortality database were used to examine time trends in incidence and mortality rates.

\section{Cancer in five continents (CI5)}

The CI5 series contain incidence data collected from population based cancer registries deemed to be of acceptable quality (Parkin et al., 2010). In 2006, 12\% of the world population and $8 \%$ of the Asian population were covered by population based cancer registries, but only $8 \%$ of the world population and $4 \%$ of the total population in Asia were covered by cancer registries that matched the inclusion criteria of CI5 (Ferlay et al., 2010). The CI5 series began in the 1960s with 32 registries and included Miyagi, Japan and Singapore (Chinese) as the sole Asian populations. Registries from 17 Asian countries contributed data to CI5 volumes I-X, including Bahrain, China, India, Israel, Japan, Korea, Kuwait, Kyrgyzstan, Malaysia, Oman, Pakistan, Philippines, Qatar, Saudi Arabia, Singapore, Thailand, and Viet Nam. Trends in breast cancer incidence from available registries were calculated using an online analysis tool (http://ci5.iarc.fr/ CI5plus/ci5plus.htm) available through 'CI5Plus' (Curado et al., 2007; Parkin et al., 2010).

\section{WHO cancer mortality database}

The WHO cancer mortality database, managed by IARC, contains selected cancer mortality statistics by country. The data were extracted from the WHO mortality databank, which includes deaths registered in national databases along with the underlying cause of death, as coded by the International Classification of Diseases (ICD). Trends in breast cancer mortality rates were illustrated using an online analysis tool available through the IARC website (http://www-dep.iarc.fr/WHOdb/ WHOdb.htm).

\section{Survival data: Survcan}

The IARC published survival rates (SurvCan) from 27 cancer registries in 14 countries in Africa, Asia, the Caribbean and Central America.(Sankaranarayanan et al., 2011b) The objective of SurvCan is to provide a baseline for the evaluation of future improvement in cancer diagnosis and care in developing countries.

\section{Results}

Incidence overall in Asia

The ASIR for breast cancer among Asian women was highest in western Asia (42.8), followed by south-eastern

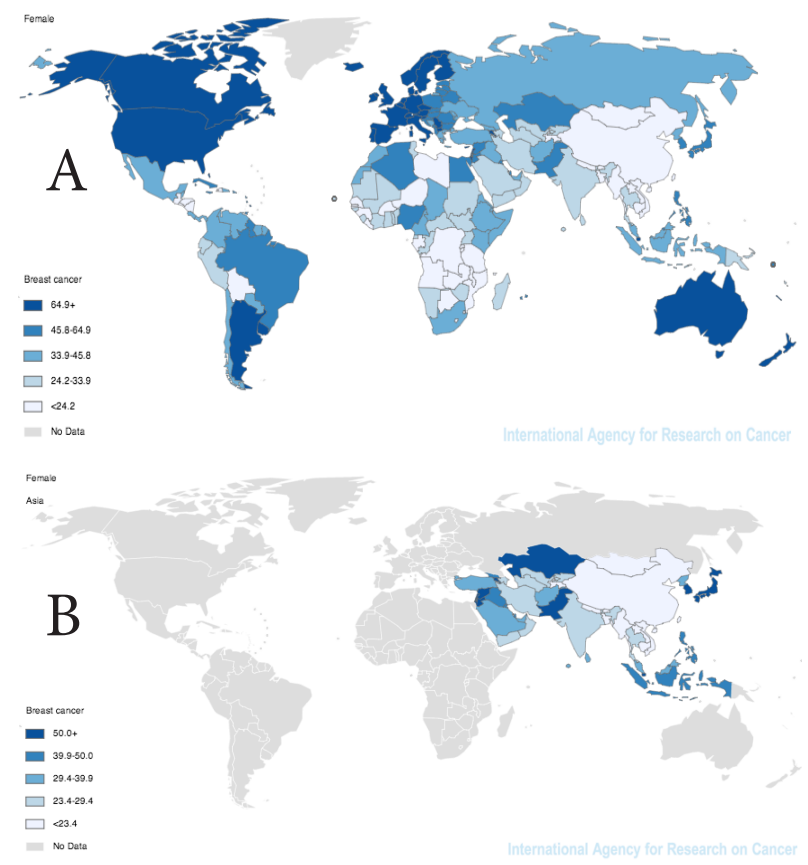

Figure 1. Age Standardized Incidence Rates (Per 100,000) of Breast Cancer among Women of All Ages Mapped by Countries and Colored by Quintiles from Globocan 2012 . (A) World (B) Asia 
Asia (34.8), south-central Asia (28.2), and eastern Asia (27.0) (Table 1) (Ferlay et al., 2013). Countries with the highest ASIR for breast cancer in Asia were Israel (80.5), Lebanon (78.7), Armenia (74.1), Singapore (65.7), Kazakhstan (63.0), Jordan (61.0), Syria (52.5), South Korea (52.1), Japan (51.5), and Pakistan (50.3); and countries with the lowest ASIR were Mongolia (9.4) and Bhutan (4.6). Based on CI5, among several Asian countries with reliable trend data, breast cancer incidence has increased steadily in all countries including South
Korea, Taiwan, China, Singapore, Thailand, Japan and Philippines (in order of increasing rates) (Parkin et al., 2010; Shin et al., 2010b; Jung et al., 2013), with the notable exception of breast cancer incidence among Israeli Jews which has generally been decreasing since 1999 after a period of increase (Figure 2) (Keinan-Boker et al., 2013).

\section{Eastern Asian countries}

Countries in eastern Asia had the lowest overall breast cancer incidence by region (27.0), although this rate was

Table 1. Breast Cancer Incidence in 47 Asian Countries ${ }^{a}$

\begin{tabular}{|c|c|c|c|c|}
\hline Region & Country & No. Cases & $\mathrm{CR}$ & ASIR \\
\hline \multirow[t]{6}{*}{ Eastern Asia } & & 277,054 & 36 & 27 \\
\hline & Korea, Republic of & 17,140 & 70.3 & 52.1 \\
\hline & Japan & 55,710 & 85.9 & 51.5 \\
\hline & Korea, Democratic Republic of* & 5,707 & 45.7 & 36.8 \\
\hline & China & 187,213 & 28.6 & 22.1 \\
\hline & Mongolia & 125 & 8.7 & 9.4 \\
\hline \multirow[t]{12}{*}{ South-Eastern Asia } & & 107,545 & 35.3 & 34.8 \\
\hline & Singapore & 2,524 & 96.8 & 65.7 \\
\hline & Brunei & 83 & 40.6 & 48.6 \\
\hline & Philippines & 18,327 & 38.1 & 47 \\
\hline & Indonesia & 48,998 & 39.9 & 40.3 \\
\hline & Malaysia & 5,410 & 37.4 & 38.7 \\
\hline & Timor-Leste* & 108 & 18.6 & 32.6 \\
\hline & Thailand & 13,653 & 38.4 & 29.3 \\
\hline & Viet Nam & 11,067 & 24.4 & 23 \\
\hline & Myanmar* & 5,648 & 22.9 & 22.1 \\
\hline & Cambodia* & 1,255 & 17 & 19.3 \\
\hline & Lao PDR* & 472 & 14.8 & 19 \\
\hline \multirow[t]{15}{*}{ South-Central Asia } & & 223,899 & 25.3 & 28.2 \\
\hline & Kazakhstan* & 6,252 & 73.5 & 63 \\
\hline & Pakistan & 34,038 & 38.4 & 50.3 \\
\hline & Afghanistan* & 3,108 & 19.3 & 35.1 \\
\hline & Maldives & 41 & 25.5 & 31.6 \\
\hline & Sri Lanka & 3,955 & 36.8 & 30.9 \\
\hline & Iran, Islamic Republic of & 9,795 & 26.3 & 28.1 \\
\hline & Kyrgyzstan* & 662 & 24 & 27.3 \\
\hline & Uzbekistan* & 3,370 & 23.9 & 27.1 \\
\hline & Turkmenistan* & 656 & 25 & 26.8 \\
\hline & India & 144,937 & 23.8 & 25.8 \\
\hline & Bangladesh & 14,836 & 19.7 & 21.7 \\
\hline & Tajikistan* & 520 & 14.4 & 20.4 \\
\hline & Nepal* & 1,716 & 11 & 13.7 \\
\hline & Bhutan & 13 & 3.7 & 4.6 \\
\hline \multirow[t]{18}{*}{ Western Asia } & & 42,485 & 36.6 & 42.8 \\
\hline & Israel & 4,010 & 103 & 80.5 \\
\hline & Lebanon & 1,934 & 88 & 78.7 \\
\hline & Armenia* & 1,704 & 102.5 & 74.1 \\
\hline & Jordan & 1,237 & 39.4 & 61 \\
\hline & Syrian Arab Republic* & 4,140 & 39.7 & 52.5 \\
\hline & Kuwait & 314 & 26.9 & 46.7 \\
\hline & Qatar & 148 & 31.6 & 46.1 \\
\hline & State of Palestine & 1,541 & 67.7 & 44 \\
\hline & Georgia* & 578 & 27.5 & 44 \\
\hline & Iraq * & 4,542 & 27.1 & 42.6 \\
\hline & Bahrain & 177 & 34.7 & 42.5 \\
\hline & United Arab Emirates* & 568 & 22.8 & 39.2 \\
\hline & Turkey & 15,230 & 40.8 & 39.1 \\
\hline & Saudi Arabia & 2,791 & 21.7 & 29.5 \\
\hline & Yemen & 1,963 & 15.5 & 27.4 \\
\hline & Oman & 195 & 16.4 & 26 \\
\hline & Azerbaijan* & 1,413 & 29.7 & 25.4 \\
\hline
\end{tabular}

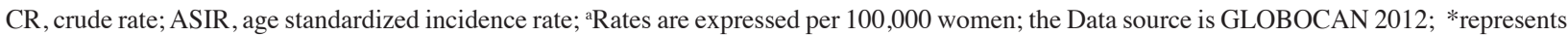
that no incidence rates from the countries were available 


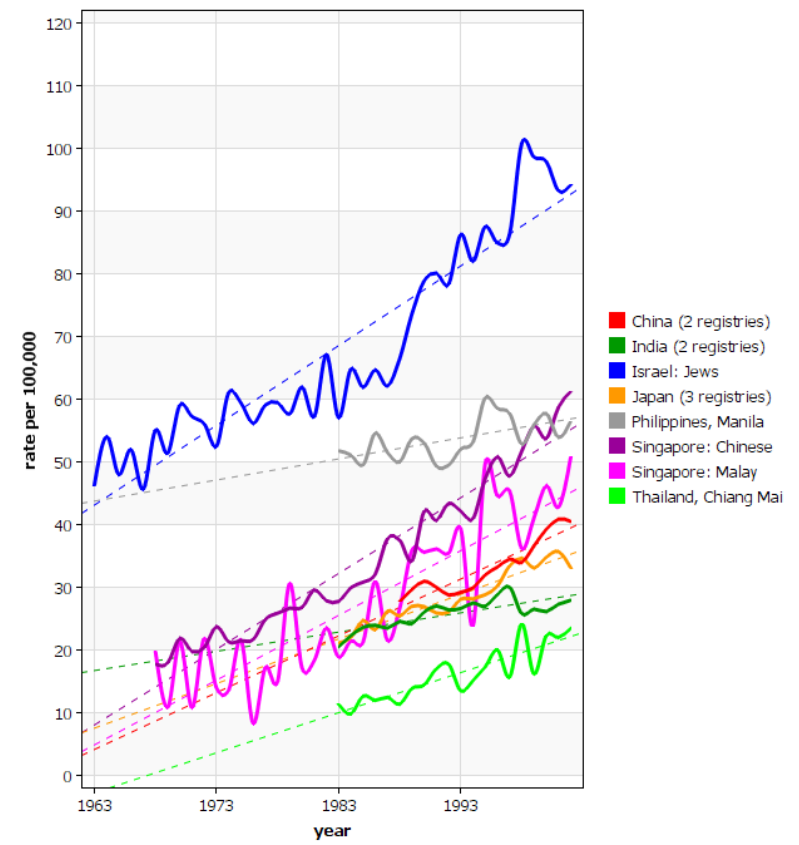

Figure 2. Trends of Age Standardized Breast Cancer Incidence Rates in Several Asian Countries from 1963 to 2002 in the CI5

heavily influenced by China with an ASIR of 22.1, much lower than that in South Korea (52.1) and Japan (51.5). South Korean women experienced the sharpest increase in breast cancer incidence during the past decade, with a 47.5\% change from 1999 through 2010 (Jung et al., 2013). By contrast, breast cancer incidence increased by $30.8 \%$ in China (including Hong Kong and Shanghai) between 1988 and 2002, and 12.0\% in Japan between 1983 and 2002 (Figure 2). The increasing incidence of breast cancer in China between 1993 and 2002 appeared much more modest in rural China (14.6\%) than in urban Shanghai (29.3\%) (Shin et al., 2010b). Breast cancer ASIR among Taiwanese women was increased from 12.75 during the period 1980-1984 to 44.45 during the period 2000-2006 (35.7\%) (Chiang et al., 2010).

\section{South-eastern Asian countries}

South-eastern Asian countries had moderate rates for breast cancer ( 34.8 by region), with higher incidence in Singapore, Brunei, Philippines, Indonesia, and Malaysia than in Viet Nam, Myanmar, Cambodia, and Laos (Table 1). In Singapore, the rate for breast cancer has been increasing rapidly, with substantial changes in incidence among both Chinese (71.0) and Malay (61.1\%) women between 1968 and 2002 (Figure 2). Increases in breast cancer incidence among women in Manila (4.7\%) and Chiang Mai (12.1\%), were much smaller during the observation period.

\section{South-central Asian countries}

Breast cancer incidence rates in south-central Asian countries were divergent, with a high of 63.0 in Kazakhstan to a low of 4.6 in Bhutan (Table 1). These data must be treated with some caution, however, as 7 of the 14 south-central Asian countries had no cancer registry data on which to base rates.

\section{Western Asian countries}

The ASIR for breast cancer in western Asian countries was higher than the Asian average of 29.1, with the exception of Yemen, Oman, and Azerbaijan (Table 1). Moreover, breast cancer rates in Israel (80.5) and Lebanon (78.7) are comparable to rates in Canada (79.8) and Australia/New Zealand (85.8) (Ferlay et al., 2013). Breast cancer incidence among Kuwaiti women increased from 15.9 during the period $1979-1982$ to 41.3 during the period 1998-2002 (Muir et al., 1987; Parkin et al., 1992; Parkin et al., 1997; Parkin et al., 2002; Curado et al., 2007). By contrast, breast cancer incidence among Israeli Jews has increased irregularly since 1963, with a slight downturn in more recent years (Figure 2). A join-point analysis using data from the Israel National Cancer Registry from 1996 to 2007 , suggested that the incidence of invasive breast cancer decreased by $3 \%$ among Jewish women, while rates increased by $98 \%$ among Arab women (Keinan-Boker et al., 2013). Nonetheless, breast cancer incidence among Palestinians (44.0) remains about half that observed among Jewish Israeli women.

\section{Age-specific incidence rates in Asian countries}

Distinct patterns were apparent in the age-specific incidence rates for breast cancer in Asian countries between 2003 and 2007 (Figure 3). In general, the incidence rates increased sharply to a peak at menopause and then were decreased or were stable. This is in contrast to age-specific breast cancer rates in the US, UK, Denmark and New Zealand in which the rates increased according to age. In Japan, China (Jiashan) and South Korea, the
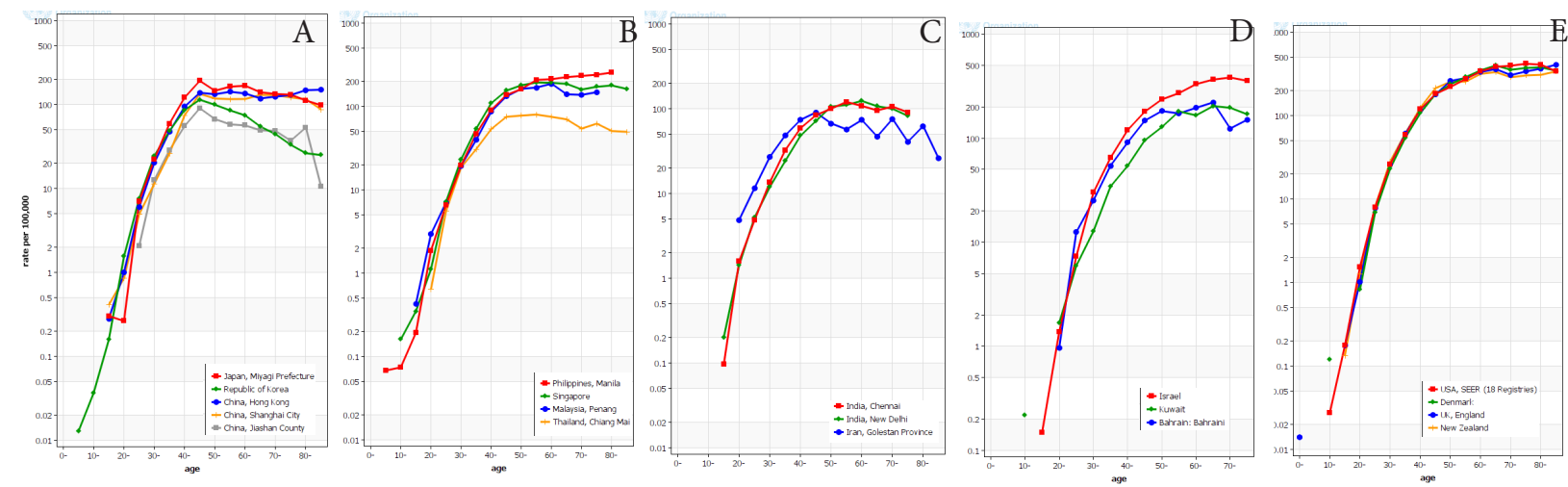

Figure 3. Age-specific Cancer Incidence Rates (per 100,000) of Breast Cancer in Asian Countries from 2003 to 2007 in CI5X. (A) Eastern Asia (B) South-eastern Asia (C) South-central Asia (D) Western Asia (E) America, Europe and Oceania 
Variation in Breast Cancer Incidence, Mortality and Survival within Asia

Table 2. Age Standardized Incidence Rate, Mortality Rate, and Mortality-to-Incidence Ratio of Breast Cancer by Regions in the World ${ }^{a}$

\begin{tabular}{|c|c|c|c|}
\hline Region/ Category & $\begin{array}{c}\text { Incidence } \\
\text { (per 100,000) }\end{array}$ & $\begin{array}{c}\text { Mortality } \\
\text { (per 100,000) }\end{array}$ & Mortality-to-Incidence ratio \\
\hline World & 43.3 & 12.9 & 0.3 \\
\hline $\begin{array}{l}\text { Asia } \\
\text { Eastern Asia } \\
\text { South-Central Asia } \\
\text { South-Eastern Asia } \\
\text { Western Asia }\end{array}$ & $\begin{array}{l}29.1 \\
27 \\
28.2 \\
34.8 \\
42.8\end{array}$ & $\begin{array}{r}10.2 \\
6.1 \\
13.5 \\
14.1 \\
15.1\end{array}$ & $\begin{array}{l}0.35 \\
0.23 \\
0.48 \\
0.41 \\
0.35\end{array}$ \\
\hline $\begin{array}{l}\text { America } \\
\text { Caribbean } \\
\text { Central America } \\
\text { South America } \\
\text { Northern America }\end{array}$ & $\begin{array}{c}- \\
46.1 \\
32.8 \\
52.1 \\
91.6\end{array}$ & $\begin{array}{c}- \\
15.1 \\
9.5 \\
14 \\
14.8\end{array}$ & $\begin{array}{l}- \\
0.33 \\
0.29 \\
0.27 \\
0.16\end{array}$ \\
\hline $\begin{array}{l}\text { Europe } \\
\text { Central and Eastern Europe } \\
\text { Northern Europe } \\
\text { Southern Europe } \\
\text { Western Europe }\end{array}$ & $\begin{array}{l}71.1 \\
47.7 \\
89.4 \\
74.5 \\
96\end{array}$ & $\begin{array}{l}16.1 \\
16.5 \\
16.3 \\
14.9 \\
16.2\end{array}$ & $\begin{array}{l}0.23 \\
0.35 \\
0.18 \\
0.2 \\
0.17\end{array}$ \\
\hline $\begin{array}{l}\text { Oceania } \\
\text { Australia/New Zealand } \\
\text { Melanesia } \\
\text { Micronesia/Polynesia }\end{array}$ & $\begin{array}{l}79.2 \\
85.8 \\
41 \\
59.7\end{array}$ & $\begin{array}{l}15.6 \\
14.5 \\
19.7 \\
13.1\end{array}$ & $\begin{array}{l}0.2 \\
0.17 \\
0.48 \\
0.22\end{array}$ \\
\hline $\begin{array}{l}\text { Africa } \\
\text { Eastern Africa } \\
\text { Middle Africa } \\
\text { Northern Africa } \\
\text { Southern Africa } \\
\text { Western Africa }\end{array}$ & $\begin{array}{l}36.2 \\
30.4 \\
26.8 \\
43.2 \\
38.9 \\
38.6\end{array}$ & $\begin{array}{l}17.3 \\
15.6 \\
14.8 \\
17.4 \\
15.5 \\
20.1\end{array}$ & $\begin{array}{l}0.48 \\
0.51 \\
0.55 \\
0.4 \\
0.4 \\
0.52\end{array}$ \\
\hline $\begin{array}{l}\text { Less developed regions } \\
\text { More developed regions }\end{array}$ & $\begin{array}{l}31.3 \\
74.1\end{array}$ & $\begin{array}{l}11.5 \\
14.9\end{array}$ & $\begin{array}{l}0.37 \\
0.2\end{array}$ \\
\hline $\begin{array}{l}\text { Low Human Development } \\
\text { Medium Human Development } \\
\text { High Human Development } \\
\text { Very High Human Development }\end{array}$ & $\begin{array}{l}32.6 \\
26.5 \\
45.2 \\
79\end{array}$ & $\begin{array}{r}17 \\
9.8 \\
14.6 \\
14.1\end{array}$ & $\begin{array}{l}0.52 \\
0.37 \\
0.32 \\
0.18\end{array}$ \\
\hline
\end{tabular}

a Data source: GLOBOCAN 2012

age-specific incidence rates increased steeply to age 45-49 years and declined thereafter. A similar pattern was observed in Iran. In contrast, in Shanghai and Hong Kong, age-specific incidence rates increased to age 4549 years and stabilized thereafter. In most south-eastern and western Asian countries, except the Philippines and Israel, the incidence for breast cancer peaked at 50-54 years followed by a plateau. In the Philippines and Israel, age-specific breast cancer incidence rates increased by age identical to the patterns observed in western countries. This data may reflect the earlier westernization in the Philippines and the large European population in Israel compared to other Asian countries.

\section{Mortality}

The age-standardized mortality rate (ASMR) for breast cancer is 12.9 worldwide, with an average ASMR for breast cancer in Asia of 10.2. Similar to breast cancer incidence, there is substantial heterogeneity in breast cancer mortality by region, with the highest mortality in western Asia (15.1), followed by south-eastern Asia (14.1), south-central Asia (13.5), and eastern Asia (6.1). Importantly, among the four Asian regions, only eastern
Asia had a lower mortality rate than the world average. Breast cancer mortality rates steadily increased in Korea, Japan, and Taiwan from 1975 to 2006 (Figure 4), while the rates slightly decreased after 1990 in Hong Kong and Singapore among women $\geq 70$ years (Shin et al., 2010a). Similarly, breast cancer mortality increased in south-eastern Asian countries, especially among Filipino women who experienced a sharp increase in death rates from 1995 through 2009 (Figure 4). Mortality trends during the 30-year period 1980 to 2009 were divergent in south-central Asian countries with large increases in breast cancer mortality in Kazakhstan, more modest increases in Turkmenistan and Uzbekistan, and only slight increases in Kyrgystan. In western Asian countries, mortality in Israel has been decreasing since 1995; whereas, mortality rates in other countries increased slightly or were too unstable for evaluation. In contrast to the increasing trend of mortality observed in most Asian countries, mortality rates for breast cancer have been declining among all age groups in Australia, Denmark, the United States, and the United Kingdom since the late-1990s.

In addition to the upswing in breast cancer mortality, an emerging concern in some parts of Asia is the high 

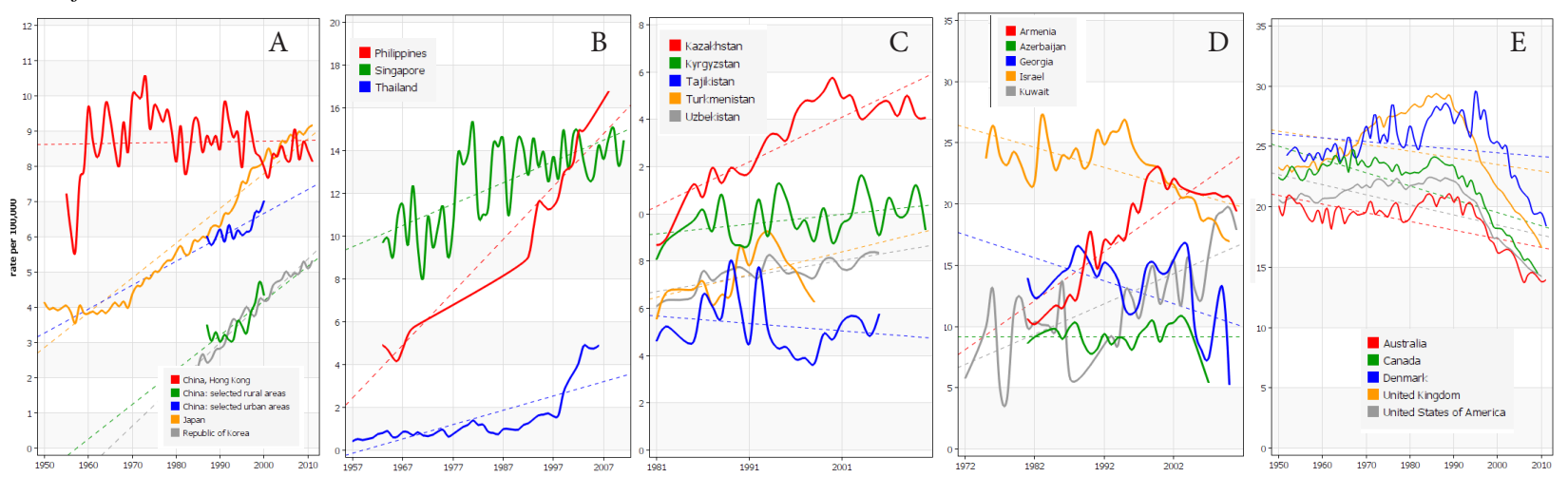

Figure 4. Trend of Age Standardized Mortality Rate (per 100,000) among Selected Countries from the WHO Cancer Mortality Database. (A) Eastern Asia (B) South-eastern Asia (C) South-central Asia (D) Western Asia (E) America, Europe and Oceania

Table 3. Five-Year Relative Survival Rate of Breast Cancer Estimated from Population Registry Data in Selected Asian Countries

\begin{tabular}{|c|c|c|c|c|}
\hline Country - Registry & Year & No. Cases & 5YR Relative Survival, \% & Source \\
\hline \multicolumn{5}{|l|}{ Eastern Asia } \\
\hline China - Hong Kong SAR & $1996-2001$ & 10,112 & 89.8 & (Sankaranarayanan et al., 2011b) \\
\hline China - Qidong & $1992-2000$ & 651 & 59.4 & (Sankaranarayanan et al., 2011b) \\
\hline China - Shanghai & 1992-1995 & 5,184 & 78.7 & (Sankaranarayanan et al., 2011b) \\
\hline China - Tianjin & 1991-1999 & 5,863 & 84.8 & (Sankaranarayanan et al., 2011b) \\
\hline Korea & 1999 & 5,537 & 83.7 & (Tanaka et al., 2009) \\
\hline Japan - Miyagi & 1997-1999 & 2,029 & 88.1 & (Tanaka et al., 2009) \\
\hline Taiwan & 1997-1999 & 11,723 & 79.7 & (Tanaka et al., 2009) \\
\hline \multicolumn{5}{|l|}{ South-eastern Asia } \\
\hline Singapore & 1993-1997 & 3,204 & 76.2 & (Sankaranarayanan et al., 2011b) \\
\hline Philippines - Manila\&Rizal & 1993-2002 & 1,615 & 58.6 & (Tanaka et al., 2009) \\
\hline Thailand - Chiang Mai & 1993-1997 & 544 & 62.1 & (Sankaranarayanan et al., 2011b) \\
\hline Thailand - Lampang & $1990-2000$ & 830 & 64.9 & (Sankaranarayanan et al., 2011b) \\
\hline \multicolumn{5}{|l|}{ South-central Asia } \\
\hline India - Mumbai & 1992-1994 & 7,294 & 51.4 & (Sankaranarayanan et al., 2011b) \\
\hline \multicolumn{5}{|l|}{ Western Asia } \\
\hline Israel (Jews) & 1990-1992 & 6,131 & 71 & (Ministry of Health Israel, 2000) \\
\hline Israel (non-jews) & 1990-1992 & 171 & 63.1 & (Ministry of Health Israel, 2000) \\
\hline Jordan & 1997-2002 & 838 & 64.2 & (Arkoob et al., 2010) \\
\hline Saudi Arabia - Riyadh & 1994-1996 & 298 & 64.5 & (Sankaranarayanan et al., 2011b) \\
\hline Turkey - Izmir & 1995-1997 & 1,329 & 76.7 & (Sankaranarayanan et al., 2011b) \\
\hline
\end{tabular}

mortality-to-incidence rate (MI) ratio for breast cancer. The MI ratio is calculated by dividing the mortality rate by the incidence rate and is an indirect measure of cancer survival - the higher the MI ratio, the lower the survival rate. Compared to the low MI ratio in North America (0.16), the lowest MI ratio in Asia was 0.23 in eastern Asia and the highest was 0.48 in south-central Asia (Table 2). This two-fold difference in the MI ratio between Asian regions might be explained by differences in economic development, i.e., higher MI ratio in less developed countries and lower MI ratio in more developed countries. While $8.8 \%$ of new breast cancer cases were diagnosed in less developed countries, $14.4 \%$ of deaths were reported from those countries. In contrast, $61.7 \%$ of incident breast cancer cases were diagnosed in highly or very highly developed countries, but only $50.8 \%$ of deaths were reported from these countries (Ferlay et al., 2013).

\section{Survival}

Breast cancer survival also varies within Asia (Sankaranarayanan et al., 2011b), which is consistent with regional differences by stage at diagnosis. In Table
3 , the 5-year relative survival rates $(\%)$ from breast cancer calculated from population-based registries in several Asian countries/cities are summarized (Ministry of Health Israel, 2000; Tanaka et al., 2009; Arkoob et al., 2010; Sankaranarayanan et al., 2011b). The five-year relative survival rate for breast cancer was highest in Hong Kong, Tianjin, Korea, and Japan (>80\%), followed by Shanghai, Taiwan, Singapore, Izmir (75-80\%), Israel (Jews) (71\%), Thailand, Israel (non-Jews), Jordan, Saudi Arabia (60$65 \%$ ), Qidong, Philippines (58-59\%), and India (51\%). Stages of breast cancer in each country are described in the Discussion

\section{Discussion}

Breast cancer rates remain comparatively low among women in Asia, but the secular trends show a rapid increase in incidence in most of the region, with the exception of Israel. A higher mortality-to-incidence ratio, more advanced stage at diagnosis, and reduced survival were observed in less developed countries than in more developed countries in Asia. The increase in breast cancer 
incidence is likely associated with changes in reproductive factors, obesity and, perhaps, enhanced medical care and breast cancer screening. A detail description of epidemiologic and clinical factors that are associated with breast cancer statistics in Asian countries are discussed in this section.

In terms of risk factors of breast cancer among Asian women, reproductive and hormone-related factors are the most studied. Results from large case-control and cohort studies conducted among women in China, Taiwan, Singapore, Japan, and South Korea suggest that women who are unmarried, nulliparous or with a reduced number of full-term pregnancies, older at first full-term pregnancy, have not breastfed, or who had an early menarche or late menopause, are at increased risk for postmenopausal breast cancer (Kato et al., 1992; Yoo et al., 1992; Chie et al., 1997; Chie et al., 1998; Chie et al., 2000; Gao et al., 2000; Zheng et al., 2000; Tamakoshi et al., 2005; Wu et al., 2006b; Kim et al., 2007; Kawai et al., 2012; Huang et al., 2013; Sugawara et al., 2013). Similar findings have been observed in smaller case-control studies conducted in other Asian countries such as Malaysia, Philippines, Thailand, India, Pakistan, and Israel (Ratanawichitrasin et al., 2002; Faheem et al., 2007; Shema et al., 2007; Gajalakshmi et al., 2009; Long et al., 2010b; Moore et al., 2010a; Moore et al., 2010b; Moore et al., 2010c; Salim et al., 2010; Lodha et al., 2011; Matalqah et al., 2011; Sulaiman et al., 2011; Bhadoria et al., 2013; Shamsi et al., 2013). Few large well-designed epidemiologic studies were conducted in countries from south-central and western Asian regions.

However, an association of oral contraceptive pill (OC) use or hormone replacement therapy (HRT) with breast cancer risk has been inconsistent between studies: an increased risk among women with a history of OC use was reported in a Taiwanese study (Chie et al., 1998) and with HRT use in a Singaporean study (Ng et al., 1997), although no association with HRT use was found among women in Japan (Saeki et al., 2008; Kawai et al., 2010), or Thailand (Ratanawichitrasin et al., 2002). Although it is likely that HRT is a risk factor for breast cancer in Asian women, as in women from other countries (Fournier et al., 2005; Chlebowski et al., 2013), in countries that have limited resources and research funding, ecologic and cross-sectional studies may assist with risk stratification (Hoel et al., 1983; Koo et al., 1997; Zhang et al., 2012).

Obesity is an established risk factor for postmenopausal breast cancer among Asian women in eastern Asia and in some countries in south-eastern Asia ( $\mathrm{Ng}$ et al., 1997; Shu et al., 2001; Yoo et al., 2001; Li et al., 2006; Jee et al., 2008; Shin et al., 2009; Shi et al., 2010; Bao et al., 2011; Sueta et al., 2012; Kawai et al., 2013; Miyagawa et al., 2013; Sangrajrang et al., 2013; Suzuki et al., 2013). Data from large prospective and case-control studies conducted in Shanghai, China, Japan, Korea, Taiwan, Singapore, and Thailand suggest that women with higher body mass indices (BMI) have a 1.5- to 2.0-fold higher risk of breast cancer compared to women with a normal BMI (Ng et al., 1997; Shu et al., 2001; Li et al., 2006; Wu et al., 2006b; Jee et al., 2008; Shin et al., 2009; Shi et al., 2010; Kawai et al., 2013; Sangrajrang et al., 2013;
Suzuki et al., 2013). Moreover, higher BMI has been associated with a higher risk of $\mathrm{ER}+/ \mathrm{PR}+$ and/or luminal type cancer among Chinese and Japanese women (Yoo et al., 2001; Bao et al., 2011; Sueta et al., 2012; Miyagawa et al., 2013). In studies among Chinese women, overweight/ obesity explained $9 \%$ of the variation in postmenopausal breast cancer risk in urban areas and $6 \%$ of the variation in breast cancer risk among women in rural areas (Wang et al., 2012a). Furthermore, weight reduction improved breast cancer survival (Chen et al., 2010).

While adolescent obesity may be related to an increased risk of postmenopausal breast cancer, epidemiologic studies conducted in Asia have produced limited data in this regard. Further research regarding the role of body fat accumulation or overweight/obesity among teenagers in the development of premenopausal breast cancer among Asian women is needed for health planning purposes, since about half of the breast cancers are detected among women $\leq 50$ years in most Asian countries. Although large prospective studies of breast cancer incidence have been conducted in several eastern Asian countries, prospective studies with sufficient power to identify risk factors for premenopausal breast cancer are generally lacking.

Aside from body weight, physical activity has been associated with a reduced risk of postmenopausal breast cancer among Chinese and Japanese women (Matthews et al., 2001; Adams et al., 2006; Suzuki et al., 2008; Gao et al., 2009; Shin et al., 2009; Pronk et al., 2011; Suzuki et al., 2011; Kawai et al., 2013). Population-based intervention studies to measure the impact of weight control and exercise on risk reduction and management of breast cancer in Asian populations are needed.

The association between dietary factors and breast cancer risk among Asian women has been a interesting research topic due to the rapid changes and unique culture of dietary habits among Asians. Based on time-trend analyses of national health data or ecologic studies, it has been posited that changes in dietary habits to a more western style (i.e., higher intake of calorie, fat, animal protein) correlate with an increased breast cancer incidence among women residing in Asian countries (Kim et al., 2009; El-Basmy et al., 2012; Mizota and Yamamoto, 2012). In large cohort studies however, this association has not been consistent: an increased risk of breast cancer was observed among Shanghai women in association with a higher intake of animal-derived fat (Kallianpur et al., 2008); whereas, fat consumption was not associated with breast cancer risk among Japanese women (Wakai et al., 2005). In a prospective study in Korea, serum total cholesterol level was associated with a $31 \%$ higher risk of breast cancer among postmenopausal Korean women (Ha et al., 2009).

Unique dietary habits that can be observed traditionally among eastern Asian women are higher intake of soy products and green tea. In the Shanghai Women's health study, breast cancer risk was inversely associated with the intake of soy products (Lee et al., 2009). Among Japanese, a similar inverse association was observed in three cohort studies (Yamamoto et al., 2003; Iwasaki et al., 2008; Wada et al., 2013), but the association was not significant in two other cohort studies (Key et al., 1999; Nishio et al., 2007). 
Among Korean women, an inverse relation between soy intake and breast cancer was observed in two case-control studies (Do et al., 2007; Cho et al., 2010). In addition, higher soy intake contributed to both reduced recurrence and mortality from breast cancer in a large populationbased case-control study among Chinese women (Shu et al., 2009). A higher intake of green tea was associated with a reduced risk of breast cancer among Chinese (Dai et al., 2010), but not among Japanese women (Iwasaki et al., 2010a; Iwasaki et al., 2010b; Iwasaki et al., 2014). Dietary intervention studies with soy and green tea among high consumers will provide information on the acute effects of constituent compounds on endogenous hormone concentrations associated with breast cancer development.

Genetic factors, such as polymorphisms, family history, and BRCA mutation, and their relation to breast cancer risk among Asian women were reported from previous studies. In a consortium including 23,637 breast cancer patients and 25,579 controls of East Asian ancestry, a replication study was conducted of 70 singlenucleotide polymorphisms (SNPs) in 67 independent breast cancer susceptibility loci identified by genome-wide association study (GWAS) primarily in European-ancestry populations (Zheng et al., 2013). In the study (Zheng et al., 2013), only half of the genetic risk variants initially reported in whites were associated with breast cancer risk in the East Asian population; whereas five breast cancer associated SNPs initially identified among Asians (Zheng et al., 2009; Long et al., 2010a; Cai et al., 2011; Long et al., 2012), were replicated in samples of whites which were variants at $6 \mathrm{q} 25,10 \mathrm{q} 21,11 \mathrm{q} 24$, and 16q12. In other GWAS studies among Asians, new breast cancer risk variants at 6q14, 10q25, and 2q34 were discovered (Kim et al., 2012; Shi et al., 2013). SNPs in several genes (i.e., XRCC1, EGFR, ATM, TP53) may be associated with breast cancer risk among Asian women, but sample sizes have been limited (Park et al., 2003; Hirose et al., 2004; Lee et al., 2005; Yuan et al., 2005; Hong et al., 2009; Faghani et al., 2011; Bag et al., 2012; Han et al., 2012; Al Mutairi et al., 2013). Although results from small case-control studies suggest gene-environment interactions for breast cancer risk among Asian women, no significant interactions were observed with a cumulative genetic risk score of 20 susceptibility loci for breast cancer and known risk factors (reproductive factors, BMI, waist-to-hip ratio, etc.) in the Shanghai Breast Cancer Genetics Study (Li et al., 2013). It will be necessary to investigate the ethnic-specific impact of SNPs on breast cancer development and treatment with substantially larger datasets in order to produce reliable and valid information specific to Asian race/ethnicity. A further challenge is that genetics may vary substantially across Asian subgroups that have lived in geographically isolated areas.

A strong scientific consensus exists that family history of breast cancer is associated with an increased risk of breast cancer, although the risk estimates differ by country, ranging from a 1.5 - to 2.0 -fold increased risk among Chinese, Japanese, and Korean women (Kato et al., 1992; Kim et al., 2007; Kilfoy et al., 2008) and a 4.0- to 5.0-fold increased risk of breast cancer among Taiwanese and Indian women (Yang et al., 1997; Lodha et al.,
2011). Studies with higher risk estimates were generally smaller case-control studies, suggesting that the familial associations may have been overestimated.

The mutation rate of BRCA1 and BRCA2 genes among high risk breast cancer patients who were suspected to have hereditary breast/ovarian cancer also varies by country, ranging from $3.8 \%$ in Hong Kong (BRCA1) (Tang et al., 1999), 5.1\% in Iran (BRCA1) (Kooshyar et al., 2013), 7.6\% in northwest China (BRCA1/2) (Ou et al., 2013), 7.8\% in Indonesia (BRCA1/2) (Purnomosari et al., 2007), 8.6\%-12.7\% in Korea (BRCA1/2) (Ahn et al., 2004; Son et al., 2012), and 26.7\% in Japan (BRCA1/2) (Sugano et al., 2008). The BRCA1 and BRCA2 mutation rates among all breast cancer cases were $1.1 \%$ in Shanghai (Suter et al., 2004) and 2.8\% in Korea (Ahn et al., 2004).

Based on the observed increases in the incidence and mortality from breast cancer, guidelines for breast cancer screening have been implemented in clinics throughout Asia, generally including bi-annual mammography screening among women older than 40 years (Leong et al., 2010). Moreover, some countries such as Korea, Singapore, and Taiwan have implemented nationwide screening programs managed by the government (Wang, 2003; Wu et al., 2006a; Kim et al., 2011). Breast cancer mammography screening rates differ by countries in Asia: $21.7 \%$ in China in 2010 (Wang et al., 2013), 26.4\% in Taiwan in 2009 (Wu et al., 2012), 23.8\% in Japan in 2009, and $51.4 \%$ in Korea in 2009 (OECD, 2011). However, facilities for routine mammographic breast screening are lacking in middle- and low-resource countries such as India (Khokhar, 2012; Shetty, 2012).

Some studies examined the effectiveness of mammography among Asians. A study from Taiwan tested the validity of a two-stage mammography screening programme, and the area under the receiver (AUC) operating characteristic curve was acceptable at $71 \%(\mathrm{Wu}$ et al., 2006a). Moreover, the positive predictive value of recall after mammography was $14 \%$, much higher than the $8 \%$ recall for selective screening and $2 \%$ recall for physical examination (Wu et al., 2006a). More cases were detected at a lower stage among mammography users than non-users in a Singapore study (Ng et al., 1998). Asian women tend to have denser breasts which might increase the false-negativity of mammography. Test sensitivity was increased with the use of supplementary ultrasonography in Taiwan and Singapore (Hou et al., 2002; Leong et al., 2012). In a study of 14,483 Thai women, the addition of ultrasonography to mammography increased the breast cancer detection rate, especially among women aged 40-59 years with non-fatty, dense breasts (Korpraphong et al., 2013).

In many Asian countries, mammographic screening is available only in a limited number of hospitals and it is affordable only to a small fraction of people in the country. In those countries, annual clinical breast examination alone may be another cost-effective option. A randomized trial to evaluate the efficiency of clinical breast examination (CBE) has been conducted in India, and showed that ASIR for advanced-stage breast cancer was higher among those who didn't have CBE after 3.5 years of follow-up (Sankaranarayanan et al., 2011a). In 
a cost-effective analysis based on data from India, CBE performed annually from ages 40 to 60 was predicted to be nearly as efficacious as biennial mammography screening for reducing breast cancer mortality while incurring only half the net costs (Okonkwo et al., 2008).

Training health staff and raising public awareness were useful and cost-effective in down-staging of breast cancer in a study conducted in Malaysia (Devi et al., 2007). However, breast self-examination didn't reduce mortality from breast cancer in China (Thomas et al., 2002). For women who live in countries/territories with limited resources and/or have strong cultural barriers to getting screened for breast cancer, such as reliance on alternative medicine, public education is necessary to reduce the morbidity and mortality from breast cancer (Seow et al., 1997; Anderson et al., 2011; Erwin et al., 2011; Huang et al., 2011; Shaheen et al., 2011; Wee and Koh, 2011).

Some researchers developed breast cancer prediction models among Asian women. Mathematical models to estimate breast cancer risk specific to Asian women have been developed among Korean women and a multi-ethnic population in Singapore (Gao et al., 2012; Park et al., 2013). A Korean model was independently developed using the risk estimates extracted from a large Korean case-control study and was assessed in two Korean cohort studies, which showed AUCs of 0.61 and 0.89 (Park et al., 2013). The Singapore model, which was a modified Gail model, found that the inclusion of age at menarche, age at first birth, and the number of first degree relatives with breast cancer performed fairly well with associated concordance statistics of 0.60 (Gao et al., 2012). In addition to the known factors, 12 SNPs were included to a risk assessment model among Chinese women, with a c-statistic of 0.63 after adjustment for over-fitting (Zheng et al., 2010). Asian-specific breast cancer risk assessment models would be useful especially in less developed countries with meager resources (Lertkhachonsuk et al., 2013), but the role of such models in counseling women regarding their risk of breast cancer needs to be validated in several diverse Asian populations. It is likely that risk assessment will ultimately need to be tailored to particular countries or regions.

Clinical factors of breast cancer, such as median age at detection, distribution of stage at diagnosis, and prevalence of estrogen and/or progesterone receptor, were different in Asian countries. The median age at diagnosis for breast cancer among women in Asian countries is generally between 49-50 years. In large size case studies or population registry data, the median age at diagnosis for breast cancer was 49-50 years in South Korea, Singapore, Malaysia, and Hong Kong, China, India (Tan et al., 2009; Ghosh et al., 2011; Jung et al., 2011; Kwong et al., 2011), but 57 years among Japanese women (Sonoo and Noguchi, 2008). In some countries, such as Indonesia, women are diagnosed at a younger age (median 47 years) ( $\mathrm{Ng}$ et al., 2011). Ranges of median ages reported from western Asian countries are between 45 and 52 years (El Saghir et al., 2007; Najjar and Easson, 2010), and the weighted median age among 8 Arab countries was 49 years (Najjar and Easson, 2010). Asian women were about 6-18 years younger at breast cancer diagnosis than non-Hispanic

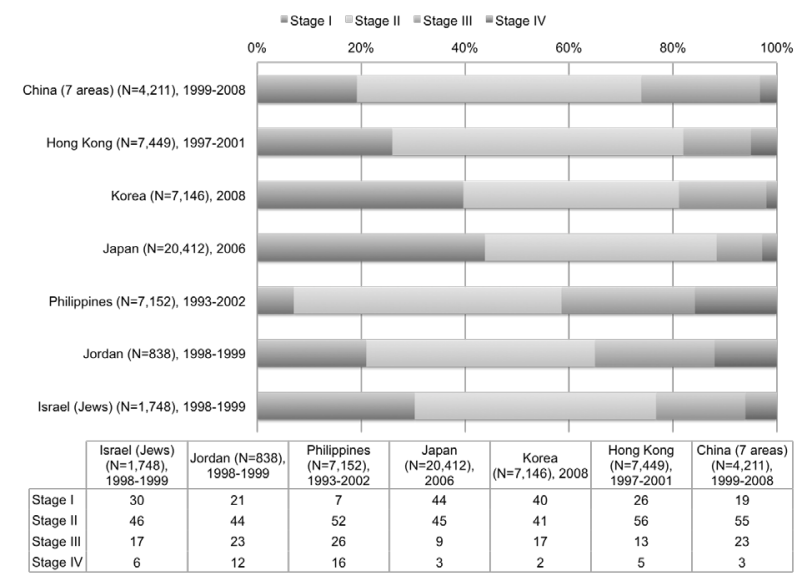

Figure 5. Distribution of Stage at Diagnosis of Breast Cancer in China, South Korea, Japan, Philippines, Jordan, and Israel (Jews). Stage distribution was calculated among cases of stages reported; data sources: China (Wang et al., 2012b), Hong Kong (Kwong et al., 2011), Korea (Jung et al., 2011), Japan (Sonoo and Noguchi, 2008), Philippines (Laudico et al., 2009), Jordan (Arkoob et al., 2010), Israel (Rennert et al., 2007)

whites (median age 63), and are younger than Asians (median age 56) in the United States (Yi et al., 2012). It has been suggested that the early onset of Asian women is explained by an age-period-cohort effect: the rapid change of breast cancer risk profiles allied to westernized lifestyle such as low parity, insufficient breastfeeding, and weight gain are observed among younger and more recently born women, which have resulted in a higher increase of breast cancer in the generation (Minami et al., 2004; Chia et al., 2005; Shen et al., 2005; Dhillon et al., 2011; MousaviJarrrahi et al., 2013).

Stage at diagnosis reflects access to and sophistication of medical care, cancer screening, as well as tumor aggressiveness. The distribution of breast cancer cases by stage at diagnosis differs considerably between Asian countries (Figure 5). The percentage of breast cancers diagnosed at an early stage (stage I and II) was relatively high in Japan (89\%), Hong Kong (82\%), and Korea ( $81 \%$ ), followed by Israel (Jews) $(76 \%)$ and China (74\%), but lower in Jordan (66\%) and the Philippines (59\%) (Rennert et al., 2007; Sonoo and Noguchi, 2008; Laudico et al., 2009; Arkoob et al., 2010; Ghosh et al., 2011; Jung et al., 2011; Kwong et al., 2011; Wang et al., $2012 b)$. Population-based data are difficult to obtain from less developed countries. A case series study from a single center in Indonesia including 637 breast cancer cases, suggested that many women were diagnosed at advanced stages: $41 \%$ stage III and $22 \%$ stage IV ( $\mathrm{Ng}$ et al., 2011). In population registry data from Singapore and Thailand, the proportion of local, regional, and distant cancer was $53 \%$, $39 \%$, and $9 \%$ in Singapore compared with 30\%, 50\%, and 9\% in Thailand, respectively (Tan et al., 2009; Kotepui and Chupeerach, 2013). The percentage of women diagnosed with breast cancer at an 'unknown' stage was higher in less developed countries: $34 \%$ in Indonesia and $28 \%$ in the Philippines compared with $14 \%$ to $17 \%$ in Hong Kong, Mainland China, Israel, Jordan, and $<10 \%$ in Japan and Korea. Studies conducted in less developed countries in Asia show that women diagnosed with breast cancer at a 
late stage tend to be older, lower socioeconomic status, lower family income, less educated, live in rural areas, and have a greater time to referral and greater number of consultations with a surgeon before diagnosis (Wang et al., 2012b; Poum et al., 2014).

Estrogen positive $(\mathrm{ER}+)$ breast cancer was the most common subtype among women in Japan (76\%), Korea (67\%), Hong Kong (66\%), Israeli Jews (59\%), and Malaysian and Singaporean Chinese (57\%) (Rennert et al., 2007; Sonoo and Noguchi, 2008; Jung et al., 2011; Kwong et al., 2011; Bhoo-Pathy et al., 2012). Malay and Indians in Malaysia and Singapore had a relatively smaller proportion of ER+ cancer $(53 \%$ in both race/ethnic groups) (Bhoo-Pathy et al., 2012). Similarly, ER+ cancer constituted $52 \%$ of breast cancer cases among Indonesian women ( $\mathrm{Ng}$ et al., 2011). Estrogen and progesterone positive $(\mathrm{ER}+\mathrm{PR}+)$ tumors represented $51 \%$ of breast cancer cases among Indian women and $48 \%$ of cases among Mainland Chinese women (Ghosh et al., 2011; Wang et al., 2012b). In contrast, estrogen negative cancer was predominant among Kuwaiti women (69\%) (Saleh and Abdeen, 2007).

In contrast to ER status, the distribution of HER2 status is more complex in Asian countries and is not consistent with survival expectation. The proportion of HER2+ breast cancer was lowest among Japanese (15\%), followed by Indians (17\%), Mainland Chinese (23\%), Malaysians (26\%), Koreans (31\%), Hong Kong Chinese (43\%), and Indonesians (45\%) (Sonoo and Noguchi, 2008; Ghosh et al., 2011; Jung et al., 2011; Kwong et al., 2011; Ng et al., 2011; Wang et al., 2012b). While HER2 positivity is generally associated with reduced breast cancer survival, HER2 status was poorly correlated with an intra-country ranking rate of breast cancer survival probabilities in Asia (see table 3 ). For example, HER 2 positivity was generally low in India (17\% of cases), a country with comparatively poor breast cancer survival, but high in Korea (31\% of cases) and Hong Kong (43\%), the country/city with the most favorable breast cancer survival probability in Asia. Although it is unclear whether the discrepancy in HER2 status between countries is biological or spurious resulting from inconsistent immunohistochemistry, ecological comparisons cannot account for other factors, such as enhanced medical care, that may also account for these putative inconsistencies.

In summary of the clinical characteristics, in contrast to less developed countries, breast cancer in more developed countries tended to be diagnosed at an earlier stage, with fewer unstaged cases, and was more likely to be ER+, suggesting that earlier detection, improved diagnosis, and better treatment options in higher resource countries contribute (Jemal et al., 2011), at least in part, to higher breast cancer survival rates.

In conclusion, breast cancer incidence in Asian countries has rapidly increased in most of the region. It is likely that morbidity and mortality from breast cancer in Asia will continue to grow, and demand for the implementation of population-based, community programmes for breast cancer prevention will expand. Increasing breast cancer awareness through health education, increasing the availability of clinical breast examination and the identification of high-risk women may be cost-effective strategies for secondary prevention in less developed regions and countries. For example, in resource-poor rural China, breast cancer rates will continue to grow among the cohort of women who reached reproductive age under the one child policy. Pilot programmes might be implemented in these areas that evaluate the efficacy of risk-stratification in the identification of women at greatest risk for a breast cancer diagnosis. An additional challenge to cancer control efforts in low resource Asian countries is to improve the quality of cancer registration, epidemiologic research, and breast cancer treatment. These efforts might be facilitated by sustained government support, health worker training programmes, and promotion of multidisciplinary treatment options utilizing available resources.

\section{References}

Adams SA, Matthews CE, Hebert JR, et al (2006). Association of physical activity with hormone receptor status: the Shanghai Breast Cancer Study. Cancer Epidemiol Biomarkers Prev, 15, 1170-8.

Ahn SH, Hwang UK, Kwak BS, et al (2004). Prevalence of BRCA1 and BRCA2 mutations in Korean breast cancer patients. J Korean Med Sci, 19, 269-74.

Al Mutairi FM, Alanazi M, Shalaby M, et al (2013). Association of XRCC1 gene polymorphisms with breast cancer susceptibility in Saudi patients. Asian Pac J Cancer Prev, 14, 3809-13.

Anderson BO, Cazap E, El Saghir NS, et al (2011). Optimisation of breast cancer management in low-resource and middleresource countries: executive summary of the Breast Health Global Initiative consensus, 2010. Lancet Oncol, 12, 387-98.

Arkoob K, Al-Nsour M, Al-Nemry O, et al (2010). Epidemiology of breast cancer in women in Jordan: patient characteristics and survival analysis. East Mediterr Health J, 16, 1032-8.

Bag A, Jyala NS, Bag N (2012). Indian studies on genetic polymorphisms and cancer risk. Indian J Cancer, 49, 144-62.

Bao PP, Shu XO, Gao YT, et al (2011). Association of hormonerelated characteristics and breast cancer risk by estrogen receptor/progesterone receptor status in the shanghai breast cancer study. Am J Epidemiol, 174, 661-71.

Bhadoria AS, Kapil U, Sareen N, et al (2013). Reproductive factors and breast cancer: A case-control study in tertiary care hospital of North India. Indian J Cancer, 50, 316-21.

Bhoo-Pathy N, Hartman M, Yip CH, et al (2012). Ethnic differences in survival after breast cancer in South East Asia. PLoS One, 7, 30995.

Bhoo-Pathy N, Yip CH, Hartman M, et al (2013). Breast cancer research in Asia: adopt or adapt Western knowledge? Eur $J$ Cancer, 49, 703-9.

Cai Q, Long J, Lu W, et al (2011). Genome-wide association study identifies breast cancer risk variant at 10q21.2: results from the Asia Breast Cancer Consortium. Hum Mol Genet, 20, 4991-9.

Chen X, Lu W, Zheng W, et al (2010). Obesity and weight change in relation to breast cancer survival. Breast Cancer Res Treat, 122, 823-33.

Chia KS, Reilly M, Tan CS, et al (2005). Profound changes in breast cancer incidence may reflect changes into a Westernized lifestyle: a comparative population-based study in Singapore and Sweden. Int J Cancer, 113, 302-6.

Chiang C-J, Chen Y-C, Chen C-J, et al (2010). Cancer Trends in Taiwan. Jpn J Clin Oncol, 40, 897-904. 
Chie W, Fu C, Lee W, et al (1997). Ages at different reproductive events, numbers of menstrual cycles in between and breast cancer risk. Oncol Rep, 4, 1039-43.

Chie WC, Hsieh C, Newcomb PA, et al (2000). Age at any fullterm pregnancy and breast cancer risk. Am J Epidemiol, 151, 715-22.

Chie WC, Li CY, Huang CS, et al (1998). Oral contraceptives and breast cancer risk in Taiwan, a country of low incidence of breast cancer and low use of oral contraceptives. Int $J$ Cancer, 77, 219-23.

Chlebowski RT, Manson JE, Anderson GL, et al (2013). Estrogen Plus Progestin and Breast Cancer Incidence and Mortality in the Women's Health Initiative Observational Study. $J$ National Cancer Institute, 105, 526-35.

Cho YA, Kim J, Park KS, et al (2010). Effect of dietary soy intake on breast cancer risk according to menopause and hormone receptor status. Eur J Clin Nutr, 64, 924-32.

Curado MP, Edwards B, Shin HR, et al 2007. Cancer Incidence in Five Continents, Vol. IX, Lyon, IARC.

Dai Q, Shu XO, Li H, et al (2010). Is green tea drinking associated with a later onset of breast cancer? Ann Epidemiol, 20, 74-81.

DeSantis C, Ma J, Bryan L, et al (2014). Breast cancer statistics, 2013. CA Cancer J Clin, 64, 52-62.

Devi B, Tang T, Corbex M (2007). Reducing by half the percentage of late-stage presentation for breast and cervix cancer over 4 years: a pilot study of clinical downstaging in Sarawak, Malaysia. Ann Oncol, 18, 1172-6.

Dhillon PK, Yeole BB, Dikshit R, et al (2011). Trends in breast, ovarian and cervical cancer incidence in Mumbai, India over a 30-year period, 1976-2005: an age-period-cohort analysis. Br J Cancer, 105, 723-30.

Do MH, Lee SS, Kim JY, et al (2007). Fruits, vegetables, soy foods and breast cancer in pre- and postmenopausal Korean women: a case-control study. Int J Vitam Nutr Res, 77, $130-41$.

El Saghir NS, Khalil MK, Eid T, et al (2007). Trends in epidemiology and management of breast cancer in developing Arab countries: a literature and registry analysis. Int J Surg, 5, 225-33.

El-Basmy A, Al-Mohannadi S, Al-Awadi A (2012). Some epidemiological measures of cancer in Kuwait: national cancer registry data from 2000-2009. Asian Pac J Cancer Prev, 13, 3113-8.

Erwin DP, Erwin DO, Ciupak G, et al (2011). Challenges and implementation of a women's breast health initiative in rural Kashmir. Breast, 20, S46-50.

Faghani M, Ghasemi FM, Nikhbakht M, et al (2011). TP53 PIN3 polymorphism associated with breast cancer risk in Iranian women. Indian J Cancer, 48, 298-302.

Faheem M, Khurram M, Jafri IA, et al (2007). Risk factors for breast cancer in patients treated at NORI Hospital, Islamabad. J Pak Med Assoc, 57, 242-5.

Ferlay J, Shin HR, Bray F, et al (2010). Estimates of worldwide burden of cancer in 2008: GLOBOCAN 2008. Int J Cancer, 127, 2893-917.

Ferlay J, Soerjomataram I, Dikshit R, et al (2015). Cancer incidence and mortality worldwide: Sources, methods and major patterns in GLOBOCAN 2012. Int J Cancer, 136, $359-86$.

Forouzanfar MH, Foreman KJ, Delossantos AM, et al (2011). Breast and cervical cancer in 187 countries between 1980 and 2010: a systematic analysis. Lancet, 378, 1461-84.

Fournier A, Berrino F, Riboli E, et al (2005). Breast cancer risk in relation to different types of hormone replacement therapy in the E3N-EPIC cohort. International J Cancer, 114, 448-54.

Gajalakshmi V, Mathew A, Brennan P, et al (2009). Breastfeeding and breast cancer risk in India: a multicenter case-control study. Int J Cancer, 125, 662-5.

Gao CM, Tajima K, Ding JH, et al (2009). Body size, physical activity and risk of breast cancer - a case control study in Jangsu Province of China. Asian Pac J Cancer Prev, 10, 877-81.

Gao F, Machin D, Chow KY, et al (2012). Assessing risk of breast cancer in an ethnically South-East Asia population (results of a multiple ethnic groups study). BMC Cancer, 12, 529.

Gao YT, Shu XO, Dai Q, et al (2000). Association of menstrual and reproductive factors with breast cancer risk: results from the Shanghai Breast Cancer Study. Int J Cancer, 87, 295-300.

Ghosh J, Gupta S, Desai S, et al (2011). Estrogen, progesterone and HER2 receptor expression in breast tumors of patients, and their usage of HER2-targeted therapy, in a tertiary care centre in India. Indian J Cancer, 48, 391-6.

Ha M, Sung J, Song YM (2009). Serum total cholesterol and the risk of breast cancer in postmenopausal Korean women. Cancer Causes Control, 20, 1055-60.

Han W, Kim KY, Yang SJ, et al (2012). SNP-SNP interactions between DNA repair genes were associated with breast cancer risk in a Korean population. Cancer, 118, 594-602.

Hirose K, Matsuo K, Toyama T, et al (2004). The CYP19 gene codon 39 Trp/Arg polymorphism increases breast cancer risk in subsets of premenopausal Japanese. Cancer Epidemiol Biomarkers Prev, 13, 1407-11.

Hoel DG, Wakabayashi T, Pike MC (1983). Secular trends in the distributions of the breast cancer risk factors--menarche, first birth, menopause, and weight--in Hiroshima and Nagasaki, Japan. Am J Epidemiol, 118, 78-89.

Hong YS, Deming SL, Gao YT, et al (2009). A two-stage casecontrol study of EGFR polymorphisms and breast cancer risk. Cancer Epidemiol Biomarkers Prev, 18, 680-3.

Hou MF, Chuang HY, Ou-Yang F, et al (2002). Comparison of breast mammography, sonography and physical examination for screening women at high risk of breast cancer in taiwan. Ultrasound Med Biol, 28, 415-20.

Huang Y, Zhou K, Li H, et al (2011). Knowledge, attitudes, and behaviour regarding breast cancer screening among women from different socio-economic regions in southwest China: a cross-sectional study. Asian Pac J Cancer Prev, 12, 203-9.

Huang Z, Beeghly-Fadiel A, Gao YT, et al (2013). Associations of reproductive time events and intervals with breast cancer risk: A report from the Shanghai Breast Cancer Study. Int J Cancer.

Iwasaki M, Inoue M, Otani T, et al (2008). Plasma isoflavone level and subsequent risk of breast cancer among Japanese women: a nested case-control study from the Japan Public Health Center-based prospective study group. J Clin Oncol, 26, 1677-83.

Iwasaki M, Inoue M, Sasazuki S, et al (2010a). Plasma tea polyphenol levels and subsequent risk of breast cancer among Japanese women: a nested case-control study. Breast Cancer Res Treat, 124, 827-34.

Iwasaki M, Inoue M, Sasazuki S, et al (2010b). Green tea drinking and subsequent risk of breast cancer in a populationbased cohort of Japanese women. Breast Cancer Res, 12, 88.

Iwasaki M, Mizusawa J, Kasuga Y, et al (2014). Green tea consumption and breast cancer risk in Japanese women: a case-control study. Nutr Cancer, 66, 57-67.

Jee SH, Yun JE, Park EJ, et al (2008). Body mass index and cancer risk in Korean men and women. Int J Cancer, 123, 1892-6.

Jemal A, Bray F, Center MM, et al (2011). Global cancer statistics. CA Cancer J Clin, 61, 69-90.

Jung KW, Won YJ, Kong H-J, et al (2013). Cancer Statistics in Korea: Incidence, Mortality, Survival and Prevalence in 
2010. Cancer Res Treat, 45, 1-14.

Jung YS, Na KY, Kim KS, et al (2011). Nation-wide Korean breast cancer data from 2008 using the breast cancer registration program. J Breast Cancer, 14, 229-36.

Kallianpur AR, Lee SA, Gao YT, et al (2008). Dietary animalderived iron and fat intake and breast cancer risk in the Shanghai Breast Cancer Study. Breast Cancer Res Treat, 107, 123-32.

Kato I, Miura S, Kasumi F, et al (1992). A case-control study of breast cancer among Japanese women: with special reference to family history and reproductive and dietary factors. Breast Cancer Res Treat, 24, 51-9.

Kawai M, Kakugawa Y, Nishino Y, et al (2012). Reproductive factors and breast cancer risk in relation to hormone receptor and menopausal status in Japanese women. Cancer Sci, 103, 1861-70.

Kawai M, Kakugawa Y, Nishino Y, et al (2013). Anthropometric factors, physical activity, and breast cancer risk in relation to hormone receptor and menopausal status in Japanese women: a case-control study. Cancer Causes Control, 24, 1033-44.

Kawai M, Minami Y, Kuriyama S, et al (2010). Reproductive factors, exogenous female hormone use and breast cancer risk in Japanese: the Miyagi Cohort Study. Cancer Causes Control, 21, 135-45.

Keinan-Boker L, Baron-Epel O, Fishler Y, et al (2013). Breast cancer trends in Israeli Jewish and Arab women, 1996-2007. Eur J Cancer Prev, 22, 112-20.

Key TJ, Sharp GB, Appleby PN, et al (1999). Soya foods and breast cancer risk: a prospective study in Hiroshima and Nagasaki, Japan. Br J Cancer, 81, 1248-56.

Khokhar A (2012). Breast cancer in India: where do we stand and where do we go? Asian Pac J Cancer Prev, 13, 4861-6.

Kilfoy BA, Zhang Y, Shu XO, et al (2008). Family history of malignancies and risk of breast cancer: prospective data from the Shanghai women's health study. Cancer Causes Control, 19, 1139-45.

Kim HC, Lee JY, Sung H, et al (2012). A genome-wide association study identifies a breast cancer risk variant in ERBB4 at 2q34: results from the Seoul Breast Cancer Study. Breast Cancer Res, 14, 56.

Kim J, Shin A, Lee JS, et al (2009). Dietary factors and breast cancer in Korea: an ecological study. Breast J, 15, 683-6.

Kim Y, Choi JY, Lee KM, et al (2007). Dose-dependent protective effect of breast-feeding against breast cancer among ever-lactated women in Korea. Eur J Cancer Prev, 16, 124-9.

Kim Y, Jun JK, Choi KS, et al (2011). Overview of the national cancer screening programme and the cancer screening status in Korea. Asian Pac J Cancer Prev, 12, 725-30.

Koo LC, Mang OW, Ho JH (1997). An ecological study of trends in cancer incidence and dietary changes in Hong Kong. Nutr Cancer, 28, 289-301.

Kooshyar MM, Nassiri M, Mahdavi M, et al (2013). Identification of germline BRCA1 mutations among breast cancer families in Northeastern Iran. Asian Pac J Cancer Prev, 14, 4339-45.

Korpraphong P, Limsuwarn P, Tangcharoensathien W, et al (2013). Improving breast cancer detection using ultrasonography in asymptomatic women with non-fatty breast density. Acta Radiol.

Kotepui M, Chupeerach C (2013). Age distribution of breast cancer from a Thailand population- based cancer registry. Asian Pac J Cancer Prev, 14, 3815-7.

Kwong A, Mang OW, Wong CH, et al (2011). Breast cancer in Hong Kong, Southern China: the first population-based analysis of epidemiological characteristics, stage-specific, cancer-specific, and disease-free survival in breast cancer patients: 1997-2001. Ann Surg Oncol, 18, 3072-8.

Laudico A, Redaniel MT, Mirasol-Lumague MR, et al (2009). Epidemiology and clinicopathology of breast cancer in metro Manila and Rizal Province, Philippines. Asian Pac J Cancer Prev, 10, 167-72.

Lee KM, Choi JY, Park SK, et al (2005). Genetic polymorphisms of ataxia telangiectasia mutated and breast cancer risk. Cancer Epidemiol Biomarkers Prev, 14, 821-5.

Lee SA, Shu XO, Li H, et al (2009). Adolescent and adult soy food intake and breast cancer risk: results from the Shanghai women's health study. Am J Clin Nutr, 89, 1920-6.

Leong LC, Gogna A, Pant R, et al (2012). Supplementary breast ultrasound screening in Asian women with negative but dense mammograms-a pilot study. Ann Acad Med Singapore, 41, 432-9.

Leong SP, Shen ZZ, Liu TJ, et al (2010). Is breast cancer the same disease in asian and western countries? World J Surg, 34, 2308-24.

Lertkhachonsuk AA, Yip CH, Khuhaprema T, et al (2013). Cancer prevention in Asia: resource-stratified guidelines from the asian oncology summit 2013. Lancet Oncol, 14, 497-507.

Li H, Beeghly-Fadiel A, Wen W, et al (2013). Gene-environment interactions for breast cancer risk among Chinese women: a report from the Shanghai Breast Cancer Genetics Study. Am J Epidemiol, 177, 161-70.

Li HL, Gao YT, Li Q, et al (2006). [Anthropometry and female breast cancer: a prospective cohort study in urban Shanghai]. Zhonghua Liu Xing Bing Xue Za Zhi, 27, 488-93.

Lodha R, Joshi A, Paul D, et al (2011). Association between reproductive factors and breast cancer in an urban set up at central India: a case-control study. Indian J Cancer, 48, 303-7.

Long J, Cai Q, Shu XO, et al (2010a). Identification of a functional genetic variant at 16q12.1 for breast cancer risk: results from the Asia Breast Cancer Consortium. PLoS Genet, 6, 1001002.

Long J, Cai Q, Sung H, et al (2012). Genome-wide association study in east Asians identifies novel susceptibility loci for breast cancer. PLoS Genet, $\mathbf{8}, 1002532$.

Long N, Moore MA, Chen W, et al (2010b). Cancer epidemiology and control in north-East Asia - past, present and future. Asian Pac J Cancer Prev, 11 Suppl 2, 107-48.

Matalqah L, Radaideh K, Yusoff ZM, et al (2011). Predictors of breast cancer among women in a northern state of Malaysia: a matched case-control study. Asian Pac J Cancer Prev, 12, 1549-53.

Matthews CE, Shu XO, Jin F, et al (2001). Lifetime physical activity and breast cancer risk in the Shanghai breast cancer study. Br J Cancer, 84, 994-1001.

Minami Y, Tsubono Y, Nishino Y, et al (2004). The increase of female breast cancer incidence in Japan: emergence of birth cohort effect. Int J Cancer, 108, 901-6.

Miyagawa Y, Miyake T, Yanai A, et al (2013). Association of body mass index with risk of luminal A but not luminal B estrogen receptor-positive and HER2-negative breast cancer for postmenopausal Japanese women. Breast Cancer.

Mizota Y, Yamamoto S (2012). Prevalence of breast cancer risk factors in Japan. Jpn J Clin Oncol, 42, 1008-12.

Moore MA, Ariyaratne Y, Badar F, et al (2010a). Cancer epidemiology in South Asia - past, present and future. Asian Pac J Cancer Prev, 11, 49-66.

Moore MA, Attasara P, Khuhaprema T, et al (2010b). Cancer epidemiology in mainland South-East Asia - past, present and future. Asian Pac J Cancer Prev, 11, 67-80.

Moore MA, Eser S, Igisinov N, et al (2010c). Cancer epidemiology and control in north-western and central asia - 
past, present and future. Asian Pac J Cancer Prev, 11, 17-32.

Mousavi-Jarrrahi SH, Kasaeian A, Mansori K, et al (2013). Addressing the younger age at onset in breast cancer patients in Asia: an age-period-cohort analysis of fifty years of quality data from the international agency for research on cancer. ISRN Oncol, 2013, 429862.

Muir CS, Waterhouse J, Mack T, et al (1987). Cancer Incidence in Five Continents, Vol. V.

Najjar H, Easson A (2010). Age at diagnosis of breast cancer in Arab nations. Int J Surg, 8, 448-52.

Ng CH, Pathy NB, Taib NA, et al (2011). Comparison of breast cancer in Indonesia and Malaysia--a clinico-pathological study between dharmais cancer centre Jakarta and university Malaya Medical Centre, Kuala Lumpur. Asian Pac J Cancer Prev, 12, 2943-6.

$\mathrm{Ng} \mathrm{EH,} \mathrm{Gao} \mathrm{F,} \mathrm{Ji} \mathrm{CY,} \mathrm{et} \mathrm{al} \mathrm{(1997).} \mathrm{Risk} \mathrm{factors} \mathrm{for} \mathrm{breast}$ carcinoma in Singaporean Chinese women: the role of central obesity. Cancer, 80, 725-31.

$\mathrm{Ng} \mathrm{EH}, \mathrm{Ng}$ FC, Tan PH, et al (1998). Results of intermediate measures from a population-based, randomized trial of mammographic screening prevalence and detection of breast carcinoma among Asian women: the Singapore Breast Screening Project. Cancer, 82, 1521-8.

Nishio K, Niwa Y, Toyoshima H, et al (2007). Consumption of soy foods and the risk of breast cancer: findings from the Japan Collaborative Cohort (JACC) Study. Cancer Causes Control, 18, 801-8.

OECD 2011. "Screening, survival and mortality for breast cancer", in Health at a Glance 2011: OECD Indicators, OECD Publishing.

Okonkwo QL, Draisma G, der Kinderen A, et al (2008). Breast Cancer Screening Policies in Developing Countries: A Cost-effectiveness Analysis for India. J National Cancer Institute, 100, 1290-300.

Ou J, Wu T, Sijmons R, et al (2013). Prevalence of BRCA1 and BRCA2 germline mutations in breast cancer women of multiple ethnic region in northwest China.J Breast Cancer, 16, 50-4.

Park B, Ma SH, Shin A, et al (2013). Korean risk assessment model for breast cancer risk prediction. PLoS One, 8, 76736.

Park SK, Kang D, Noh DY, et al (2003). Reproductive factors, glutathione S-transferase M1 and T1 genetic polymorphism and breast cancer risk. Breast Cancer Res Treat, 78, 89-96.

Parkin DM, Ferlay J, Curado MP, et al (2010). Fifty years of cancer incidence: CI5 I-IX. Int J Cancer, 127, 2918-27.

Parkin DM, Muir CS, Whelan SL, et al (1992). Cancer Incidence in Five Continents, Vol. VI.

Parkin DM, Whelan SL, Ferlay J, et al (1997). Cancer Incidence in Five Continents, Vol. VII

Parkin DM, Whelan SL, Ferlay J, et al (2002). Cancer Incidence in Five Continents, Vol. VIII.

Poum A, Promthet S, Duffy SW, et al (2014). Factors associated with delayed diagnosis of breast cancer in northeast Thailand. J Epidemiol, 24, 102-8.

Pronk A, Ji BT, Shu XO, et al (2011). Physical activity and breast cancer risk in Chinese women. Br J Cancer, 105, 1443-50.

Purnomosari D, Pals G, Wahyono A, et al (2007). BRCA1 and BRCA2 germline mutation analysis in the Indonesian population. Breast Cancer Res Treatment, 106, 297-304.

Ratanawichitrasin A, Reansuwan W, Ratanawichitrasin S, et al (2002). Risk of breast cancer in post-menopausal women using hormone replacement therapy. J Med Assoc Thai, 85, 583-9.

Rennert G, Bisland-Naggan S, Barnett-Griness O, et al (2007). Clinical outcomes of breast cancer in carriers of BRCA1 and BRCA2 mutations. $N$ Engl J Med, 357, 115-23.

Saeki T, Sano M, Komoike Y, et al (2008). No increase of breast cancer incidence in Japanese women who received hormone replacement therapy: overview of a case-control study of breast cancer risk in Japan. Int J Clin Oncol, 13, 8-11.

Saleh F, Abdeen S (2007). Pathobiological features of breast tumours in the State of Kuwait: a comprehensive analysis. $J$ Carcinogenesis, 6, 12 .

Salim EI, Moore MA, Bener A, et al (2010). Cancer epidemiology in South-West Asia - past, present and future. Asian Pac J Cancer Prev, 11, 33-48.

Sangrajrang S, Chaiwerawattana A, Ploysawang P, et al (2013). Obesity, diet and physical inactivity and risk of breast cancer in thai women. Asian Pac J Cancer Prev, 14, 7023-7.

Sankaranarayanan R, Ramadas K, Thara S, et al (2011a). Clinical breast examination: preliminary results from a cluster randomized controlled trial in India. J Natl Cancer Inst, 103, 1476-80.

Sankaranarayanan R, Swaminathan R, Lucas E (2011b). Cancer survival in Africa, Asia, the Caribbean and Central America (SurvCan), Lyon, International Agency for Research on Cancer, IARC Scientific Publications volume 162.

Seow A, Straughan PT, Ng EH, et al (1997). Factors determining acceptability of mammography in an Asian population: a study among women in Singapore. Cancer Causes Control, 8, 771-9.

Shaheen R, Slanetz PJ, Raza S, et al (2011). Barriers and opportunities for early detection of breast cancer in Gaza women. Breast, 20, 30-4.

Shamsi U, Khan S, Usman S, et al (2013). A multicenter matched case control study of breast cancer risk factors among women in Karachi, Pakistan. Asian Pac J Cancer Prev, 14, 183-8.

Shema L, Ore L, Ben-Shachar M, et al (2007). The association between breastfeeding and breast cancer occurrence among Israeli Jewish women: a case control study. J Cancer Res Clin Oncol, 133, 539-46.

Shen YC, Chang CJ, Hsu C, et al (2005). Significant difference in the trends of female breast cancer incidence between Taiwanese and Caucasian Americans: implications from age-period-cohort analysis. Cancer Epidemiol Biomarkers Prev, 14, 1986-90.

Shetty P (2012). India faces growing breast cancer epidemic. The Lancet, 379, 992-3.

Shi J, Sung H, Zhang B, et al (2013). New breast cancer risk variant discovered at 10q25 in East Asian women. Cancer Epidemiol Biomarkers Prev, 22, 1297-303.

Shi J, Zhang M, Li L, et al (2010). Body mass index and its change in adulthood and breast cancer risk in China. Asian Pac J Cancer Prev, 11, 1213-8.

Shin A, Matthews CE, Shu XO, et al (2009). Joint effects of body size, energy intake, and physical activity on breast cancer risk. Breast Cancer Res Treat, 113, 153-61.

Shin HR, Boniol M, Joubert C, et al (2010a). Secular trends in breast cancer mortality in five East Asian populations: Hong Kong, Japan, Korea, Singapore and Taiwan. Cancer Sci, 101, 1241-6.

Shin HR, Joubert C, Boniol M, et al (2010b). Recent trends and patterns in breast cancer incidence among eastern and southeastern asian women. Cancer Causes Control, 21, 1777-85.

Shu XO, Jin F, Dai Q, et al (2001). Association of body size and fat distribution with risk of breast cancer among Chinese women. Int J Cancer, 94, 449-55.

Shu XO, Zheng Y, Cai H, et al (2009). Soy food intake and breast cancer survival. Jama, 302, 2437-43.

Son BH, Ahn SH, Kim SW, et al (2012). Prevalence of BRCA1 and BRCA2 mutations in non-familial breast cancer patients with high risks in Korea: the Korean hereditary breast cancer (KOHBRA) Study. Breast Cancer Res Treat, 133, 1143-52. 
Sonoo H, Noguchi S (2008). Results of questionnaire survey on breast cancer surgery in Japan 2004-2006 [additional tables available at: http://www.jbcs.gr.jp/english_new/REPORT/ REPORT.pdf ]. Breast Cancer, 15, 3-4.

Sueta A, Ito H, Islam T, et al (2012). Differential impact of body mass index and its change on the risk of breast cancer by molecular subtype: A case-control study in Japanese women. Springerplus, 1, 39.

Sugano K, Nakamura S, Ando J, et al (2008). Cross-sectional analysis of germline BRCA1 and BRCA2 mutations in Japanese patients suspected to have hereditary breast/ovarian cancer. Cancer Sci, 99, 1967-76.

Sugawara Y, Kakizaki M, Nagai M, et al (2013). Lactation pattern and the risk for hormone-related female cancer in Japan: the Ohsaki Cohort Study. Eur J Cancer Prev, 22, 187-92.

Sulaiman S, Shahril MR, Shaharudin SH, et al (2011). Fat intake and its relationship with pre- and post-menopausal breast cancer risk: a case-control study in Malaysia. Asian Pac J Cancer Prev, 12, 2167-78.

Suter NM, Ray RM, Hu YW, et al (2004). BRCA1 and BRCA2 mutations in women from Shanghai China. Cancer Epidemiol Biomarkers Prev, 13, 181-9.

Suzuki R, Iwasaki M, Yamamoto S, et al (2011). Leisure-time physical activity and breast cancer risk defined by estrogen and progesterone receptor status--the Japan Public Health Center-based Prospective Study. Prev Med, 52, 227-33.

Suzuki S, Kojima M, Tokudome S, et al (2008). Effect of physical activity on breast cancer risk: findings of the Japan collaborative cohort study. Cancer Epidemiol Biomarkers Prev, 17, 3396-401.

Suzuki S, Kojima M, Tokudome S, et al (2013). Obesity/ weight gain and breast cancer risk: findings from the Japan collaborative cohort study for the evaluation of cancer risk. $J$ Epidemiol, 23, 139-45.

Tamakoshi K, Yatsuya H, Wakai K, et al (2005). Impact of menstrual and reproductive factors on breast cancer risk in Japan: results of the JACC study. Cancer Sci, 96, 57-62.

Tan B, Lim G, Czene K, et al (2009). Do Asian breast cancer patients have poorer survival than their western counterparts? A comparison between Singapore and Stockholm. Breast Cancer Research, 11, 1-10.

Tanaka H, Tanaka M, Chen W, et al (2009). Proposal for a cooperative study on population-based cancer survival in selected registries in East Asia. Asian Pac J Cancer Prev, 10, 1191-8.

Tang NL, Pang CP, Yeo W, et al (1999). Prevalence of mutations in the BRCA1 gene among Chinese patients with breast cancer. $J$ Natl Cancer Inst, 91, 882-5.

Thomas DB, Gao DL, Ray RM, et al (2002). Randomized Trial of Breast Self-Examination in Shanghai: Final Results. $J$ National Cancer Institute, 94, 1445-57.

Wada K, Nakamura K, Tamai Y, et al (2013). Soy isoflavone intake and breast cancer risk in Japan: from the Takayama study. Int J Cancer, 133, 952-60.

Wakai K, Tamakoshi K, Date C, et al (2005). Dietary intakes of fat and fatty acids and risk of breast cancer: a prospective study in Japan. Cancer Sci, 96, 590-9.

Wang B, He M, Wang L, et al (2013). Breast cancer screening among adult women in China, 2010. Prev Chronic Dis 10, 183.

Wang D, Zheng W, Wang SM, et al (2012a). Estimation of cancer incidence and mortality attributable to overweight, obesity, and physical inactivity in China. Nutr Cancer, 64, 48-56.

Wang Q, Li J, Zheng S, et al (2012b). Breast cancer stage at diagnosis and area-based socioeconomic status: a multicenter 10 -year retrospective clinical epidemiological study in China. BMC Cancer, 12, 122.
Wang SC (2003). The Singapore National Breast Screening Programme: principles and implementation. Ann Acad Med Singapore, 32, 466-76.

Wee LE, Koh GC (2011). The effect of neighborhood, socioeconomic status and a community-based program on multi-disease health screening in an Asian population: a controlled intervention study. Prev Med, 53, 64-9.

Wu GH, Chen LS, Chang KJ, et al (2006a). Evolution of breast cancer screening in countries with intermediate and increasing incidence of breast cancer. J Med Screen, 13, 23-7.

Wu MH, Chou YC, Yu JC, et al (2006b). Hormonal and body-size factors in relation to breast cancer risk: a prospective study of 11,889 women in a low-incidence area. Ann Epidemiol, 16, 223-9.

Wu TY, Chung S, Yeh MC, et al (2012). Understanding breast cancer screening practices in Taiwan: a country with universal health care. Asian Pac J Cancer Prev, 13, 4289-94.

Yamamoto S, Sobue T, Kobayashi M, et al (2003). Soy, isoflavones, and breast cancer risk in Japan. J Natl Cancer Inst, 95, 906-13.

Yang PS, Yang TL, Liu CL, et al (1997). A case-control study of breast cancer in Taiwan--a low-incidence area. Br J Cancer, 75, 752-6.

Yi M, Liu P, Li X, et al (2012). Comparative analysis of clinicopathologic features, treatment, and survival of Asian women with a breast cancer diagnosis residing in the United States. Cancer, 118, 4117-25.

Yoo K, Tajima K, Park S, et al (2001). Postmenopausal obesity as a breast cancer risk factor according to estrogen and progesterone receptor status (Japan). Cancer Lett, 167, 57-63.

Yoo KY, Kim Y, Park SK, et al (2006). Lifestyle, genetic susceptibility and future trends of breast cancer in Korea. Asian Pac J Cancer Prev, 7, 679-82.

Yoo KY, Tajima K, Kuroishi T, et al (1992). Independent protective effect of lactation against breast cancer: a casecontrol study in Japan. Am J Epidemiol, 135, 726-33.

Yuan JM, Koh WP, Sun CL, et al (2005). Green tea intake, ACE gene polymorphism and breast cancer risk among Chinese women in Singapore. Carcinogenesis, 26, 1389-94.

Zhang Q, Liu LY, Wang F, et al (2012). The changes in female physical and childbearing characteristics in China and potential association with risk of breast cancer. BMC Public Health, 12, 368.

Zheng T, Duan L, Liu Y, et al (2000). Lactation reduces breast cancer risk in Shandong Province, China. Am J Epidemiol, 152, 1129-35.

Zheng W, Long J, Gao YT, et al (2009). Genome-wide association study identifies a new breast cancer susceptibility locus at 6q25.1. Nat Genet, 41, 324-8.

Zheng W, Wen W, Gao YT, et al (2010). Genetic and clinical predictors for breast cancer risk assessment and stratification among Chinese women. J Natl Cancer Inst, 102, 972-81.

Zheng W, Zhang B, Cai Q, et al (2013). Common genetic determinants of breast-cancer risk in East Asian women: a collaborative study of 23637 breast cancer cases and 25 579 controls. Hum Mol Genet, 22, 2539-50. 